\title{
Variations in the branching pattern in inferior mesenteric artery: a series of five cases
}

\author{
SINGH, R.* \\ Department of Anatomy, All India Institute of Medical Sciences, Virbhadra Marg, Pashulok Rishikesh, 249201 \\ Dehradun, UK, India \\ *E-mail: nani_sahayal@rediffmail.com
}

\begin{abstract}
Introduction: Inferior mesenteric artery arises from abdominal aorta just below the third part of duodenum at the level of L3-L4 vertebra. It supplies left colon and rectosigmoid colon through its branches namely- left colic artery, two-three sigmoid arteries and superior rectal artery. The branching pattern of inferior mesenteric artery is of immense use in colon surgery. Material and Methods: The study was carried out in the department of anatomy by dissecting seven embalmed cadavers. The inferior mesenteric artery and its branches were identified; its vertebral level was analysed. The length and diameter of inferior mesenteric artery were measured by vernier callipers. Results: In first case, bifurcation of inferior mesentric artery into common trunk and main artery then trifurcation of main artery and bifurcation of common trunk belong to anomalous configuration. In second case, this artery gave a tetrafurcated common trunk and main artery which continued as superior rectal artery. In third case, the same artery trifurcated into left colic, superior rectal artery and bifurcated common trunk. In fourth case, the artery bifurcated into common trunk further dividing into left colic and sigmoid arteries and main artery into superior rectal and sigmoid arteries. In fifth case, this artery trifurcated into three branches namely, sigmoid, rectosigmoid, and superior rectal arteries. Left colic artery arose from superior mesenteric artery. Conclusion: The knowledge of branching pattern of inferior mesenteric artery will be of paramount importance to colon surgeons during colectomy, to radiologists in avoiding misinterpretation of radiographs and anatomists for new variants.
\end{abstract}

Keywords: colon, inferior mesenteric artery, rectum, sigmoid artery.

\section{Introduction}

Left colon and rectosigmoid colon are supplied by inferior mesenteric artery (IMA) and its branches, classically by means of left colic artery (LCA), 2-3 sigmoid arteries and superior rectal artery as described in standard text books of Anatomy. IMA originates anterolaterally from the left aspect of the abdominal aorta just below the third part of the duodenum at the level of $3^{\text {rd }}-4^{\text {th }}$ lumbar vertebra. It runs downwards arching slightly to the left, and after crossing the left common iliac artery, it continues as the superior rectal (or hemorrhoidal) artery. Variations in the origin of IMA have been reported in the literature (MICHELS, SIDDHARTH, KORNBLITH et al., 1965; NELSON, POLLAK, JONASSON et al., 1988; OSAWA, FENG, SASAKI et al., 2004; TERAYAMA, NAITO, IIMURA et al., 2008; YOO, KU, CHO et al., 2011). The branching patterns of IMA have limited literature. In addition to this detailed knowledge of anatomical variations of visceral branches of the abdominal aorta is of extreme clinical importance, particularly, in laparoscopic abdominal surgery and colectomy (SINKEET, PHILIP, JOHNSTONE et al., 2013). Further colonic vascular supply has some weak areas such as Griffiths' point at the left colic flexure (GRIFFITHS, 1956; YAMAZAKI, SHIRAI, SAKAI et al., 1997a) and the Sudeck's point at the rectosigmoid region (MICHELS, SIDDHARTH, KORNBLITH et al., 1965; YAMAZAKI, SHIRAI, SAKAI et al. 1997b) which have been reported to be highly predisposed to ischemic colitis (LONGO, BALLANTYNE and GUSBERG, 1992; BOWER, 1993; FARMAN, 1995). When IMA or superior mesenteric artery is stenosed/ occluded collateral channels between these arteries, it plays an important role in maintaining the vascular supply to the affected region. Patency and continuity of collateral channels, namely, colic marginal artery and inferior mesenteric artery are highly variable (SINKEET, PHILIP, JOHNSTONE et al., 2013).

Moreover, knowledge of the pattern of collateral supply also constitutes a critical point of consideration during colic resections in cases of cancer management (SINKEET, PHILIP, JOHNSTONE et al., 2013). Therefore the aim of the present study is to examine the variations in the branching pattern of IMA responsible for blood supply to the left colon and rectosigmoid regions in series of seven cadavers from India. The knowledge of variant configuration of branches of IMA will be of paramount importance to surgeons during colectomy, radiologists to avoid misinterpretation of radiographs and anatomists for new variants of IMA configuration.

\section{Material and Methods}

The study was carried out in the department of anatomy, AIIMS Rishikesh on seven embalmed cadaveric dissection by making midline incision in the anterior abdominal wall. Any specimen with demonstrable pathology or evidence of previous surgical intervention in the area of interest was excluded from the study. Small intestines were displaced to the right and parietal peritoneum covering retroperitoneal structures on 
posterior abdominal wall were cleared to further expose the mesenteric arteries and their branches. Inferior mesenteric artery was identified and its vertebral level of origin was analyzed. Length from origin to the point of bifurcation of first branch and diameter of IMA at its origin were measured by sliding vernier calipers. The configuration of branching pattern of IMA was examined by identifying branches of IMA and following them carefully to the gut wall. The variant configurations were correlated with pathologies described in published literature.

\section{Results}

In the present study branching pattern of IMA was observed in seven cadavers. In two cadavers classical branching pattern was observed. In five specimens variant configuration of branching pattern was observed which is detailed below.

\section{Specimen-1 (Fig.1)}

IMA arose at the level of L3 vertebra. Its length from origin to the point of bifurcation was $3.8 \mathrm{~cm}$ and diameter at origin was $0.6 \mathrm{~cm}$. IMA bifurcated into a common trunk and main artery continued down (Figure 1). Common trunk divided into left colic artery and sigmoid artery. Left colic artery divided into ascending and descending branches. Ascending branch anastomosed with branch of the middle colic artery. Descending branch anastomosed with the sigmoid artery. The main artery $1.0 \mathrm{~cm}$ distal to left common iliac artery trifurcated into two sigmoid arteries and superior rectal artery (Figure 1).

Specimen-2 (Fig.2)

Inferior mesenteric artery originated at vertebral level L4. The length and diameter at the origin of IMA were $5.0 \mathrm{~cm}$ and $0.6 \mathrm{~cm}$ respectively. IMA bifurcated into a common trunk and main artery continued as superior rectal artery Figure 2).

\section{Specimen-3 (Fig.3)}

Inferior mesenteric artery arose at L3 vertebra. Diameter and length of this artery at and from the origin were $0.5 \mathrm{~cm}$ and $2.5 \mathrm{~cm}$ respectively. IMA trifurcated into left colic artery, common trunk and superior rectal artery. Common trunk divided into two sigmoid arteries. Upper sigmoid artery communicated with the descending branch of left colic artery. The superior rectal artery followed classical course (Figure 3).

Specimen-4 (Fig.4)

Length of IMA was $2.8 \mathrm{~cm}$ and diameter $0.4 \mathrm{~cm}$. It arose from abdominal aorta at the level of L3 vertebra and after $2.8 \mathrm{~cm}$ bifurcated into common trunk and main artery. Further main artery bifurcated into superior rectal artery and sigmoid artery. Common trunk gave left colic and sigmoid arteries. Left colic artery anastomized with middle colic artery cranially and sigmoid artery caudally. The superior rectal artery followed usual course (Figure 4).

\section{Specimen-5}

Inferior mesenteric artery originated from abdominal aorta at the level of L3 vertebra. Diameter of IMA at the origin was $0.4 \mathrm{~cm}$ and length from origin to the point of trifurcation was
$3.2 \mathrm{~cm}$. IMA trifurcated into sigmoid artery, recto-sigmoid artery and superior rectal artery. Left colic artery arose from the superior mesenteric artery.

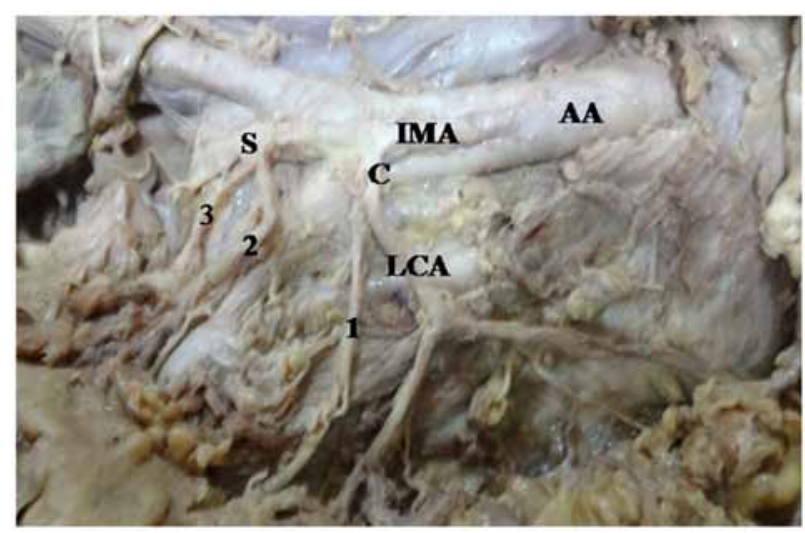

Figure 1. Showing bifurcation of inferior mesenteric artery. $\mathrm{AA}=$ Abdominal aorta $\mathrm{C}=$ Common trunk $\mathrm{LCA}=$ Left colic artery; $\mathrm{l}=$ first sigmoid artery; 2 = second sigmoid artery; 3 = third sigmoid artery; $S=$ superior rectal artery.

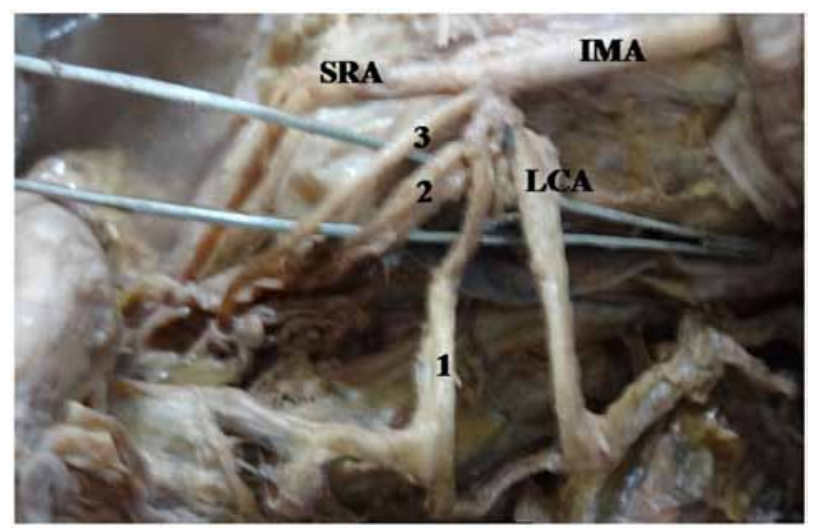

Figure 2. Showing bifurcation of inferior mesenteric artery. $\mathrm{IMA}=$ Inferior mesenteric artery; LCA = left colic artery; $\mathrm{SRA}=$ superior rectal artery; $1=$ first sigmoid artery; 2 = second sigmoid artery; 3 = third sigmoid artery.

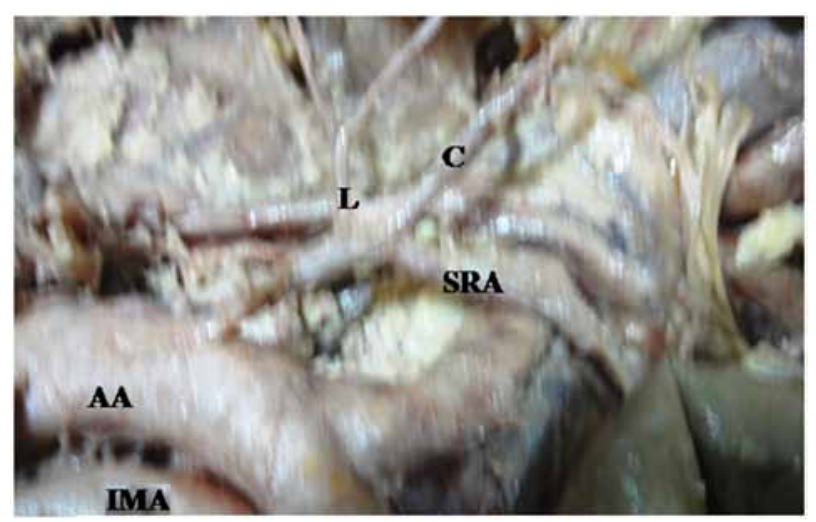

Figure 3. Showing trifurcation of inferior mesenteric artery. $\mathrm{AA}=$ Abdominal aorta; IMA $=$ Inferior mesenteric artery; $\mathrm{SRA}=$ superior rectal artery; $\mathrm{L}=$ left colic artery; $\mathrm{C}=$ common trunk. 


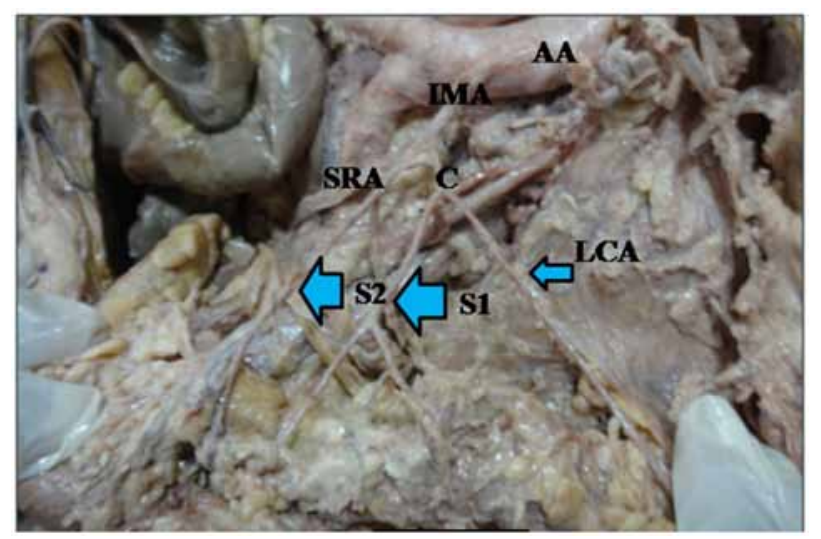

Figure 4. Showing trifurcation of inferior mesenteric artery. $\mathrm{IMA}=$ Inferior mesenteric artery; SRA = superior rectal artery; $\mathrm{L}=$ left colic artery; $\mathrm{C}=$ common trunk; $\mathrm{S} 1, \mathrm{~S} 2$-secondaries rami; $\mathrm{AA}=$ Abdominal artery.

\section{Discussion}

Present study reports the origin, length, diameter and branching pattern in series of seven cadavers of Indian origin. The mean length of IMA was $3.46 \pm 0.99$. The range of lengths was $(2.5-5.0) \mathrm{cm}$. The range in the present study lies within the reported range of (2-7) $\mathrm{cm}$ (MICHELS, SIDDHARTH, KORNBLITH et al., 1965) but narrower than this. The difference may be due to small sample space of seven cadavers. The length of IMA from its origin to the Sudeck's point is critical during ligation of the artery in colorectal surgery (BASMAJIAN, 1955). An adequately long IMA therefore will provide for feasibility and safety of such surgical procedures.

Classical branching pattern of IMA was seen only in 12\% cases (SINKEET, PHILIP, JOHNSTONE et al., 2013), 15\% of cases (GOLLIGHER, 1967) and 28.9\% (BASMAJIAN, 1955 ). In present case classical branching pattern was observed in $28.5 \%$ which is higher than that observed by Sinkeet, Philip, Johnstone et al. (2013) and Golligher (1967) but close to the study of Basmajian (1955). In specimen one in present study, IMA divided into common trunk for left colic artery and sigmoid artery which was observed in $53-56 \%$ of cases (MICHELS, SIDDHARTH, KORNBLITH et al., 1965; NELSON, POLLAK, JONASSON et al., 1988; GRIFFITHS, 1956; LONGO, BALLANTYNE and GUSBERG, 1992; BOWER, 1993; FARMAN, 1995). The main artery after travelling for $1 \mathrm{~cm}$ distal to common iliac artery trifurcated into two sigmoid arteries and superior rectal artery. There is no mention of such branching in literature. Therefore it is new pattern.

In second case- IMA gave a common trunk and main artery continued as superior rectal artery. Common trunk after $2 \mathrm{~mm}$ tetrafurcated into four branches- left colic artery and three sigmoid arteries. Such branching pattern too is new variant.

In third sample, IMA trifurcated into left colic artery, common trunk and superior rectal artery which was most frequent branching patterns of IMA observed by Sinkeet, Philip, Johnstone et al. (2013).

In fourth case- IMA bifurcated into common trunk and main artery which again bifurcated into superior rectal artery and sigmoid artery. Common trunk gave left colic and sigmoid arteries. This is another variant.
In fifth case- Left colic artery arose from superior mesenteric artery. IMA trifurcated into sigmoid artery, rectosigmoid artery and superior rectal artery. In this case there is single sigmoid artery instead of 2-3 sigmoid arteries and hence vulnerable for ischemic colitis.

Three sigmoid arteries were observed in first and second specimens, two in third and fourth specimens and only one sigmoid artery was observed in fifth specimens. Thus in fifth specimen the lower part of descending colon and sigmoid colon is least supplied and most vulnerable for ischemic colitis. Two or three sigmoid arteries have been observed in 96-73\% (MICHELS, SIDDHARTH, KORNBLITH et al., 1965; SINKEET, PHILIP, JOHNSTONE et al., 2013; GOLLIGHER, 1967; SIDDHARTH and RAVO, 1988) whereas in the present study 2-3 sigmoid arteries were observed in $60 \%$ of cases which is lower than observed by above scientists. In none of the cases macroscopic anastomosis was observed at sudeck's point.

Branching pattern of the IMA varies so much so that Bacon and Smith (1948) advocated transillumination of the mesentry in all patients prior to ligation of any vessel or determination of the surgical procedures employed during colon surgery.

Inferior mesenteric artery and its branches have been used as graft and as an alternative to the internal thoracic artery in coronary revascularization due to less atherosclerotic involvement and higher success rates (VAN TONDER, BOON, BECKER et al., 2007; CALAFIORE, DI GIAMMARCO, TEODORI et al., 1995; MIKKELSEN, 1995).

Connecting arterial channels between left colic artery and superior mesenteric artery and between left colic artery and celiac artery was observed by Sinkeet, Philip, Johnstone et al. (2013), which were not observed in any of the specimens of present study.

Division of the superior rectal artery distal to the Sudeck's point in the presence of insufficient or lacking anastomosis between the superior rectal artery and the last sigmoid branch has been reported to cause postoperative ischemic stricture (YAMAZAKI, SHIRAI, SAKAI et al., 1997a). Colorectal surgeons and other surgeons working in this region should therefore always take into consideration this fact to avoid any inadvertent assault to this precarious blood supply.

\section{Conclusion}

Variations in Branching pattern of IMA observed in the present study are not available in standard text books of anatomy and literature. Knowledge of these variations might help to account for some of the untoward outcomes observed following colon surgery. Careful attempt to delineate the branching pattern of the inferior mesenteric intraoperatively is recommended to avert possible dismal surgical outcome. An angiographic study to further delineate functionality of the arterial anastomoses in this region is recommended in living subject.

Limitations: The most important limitation of present study is small sample space of seven cadavers which may not be representative of mass population. The statistics have been computed and described in the article for an idea of incidence.

Acknowledgements: The author is grateful to director of instituteProf. Raj Kumar for allowing the work to be carried out in the institute. The author is also indebted to Mr. Man Singh father of the author in reading the manuscript critically. The author has not received and financial support from any institute with respect to article. There is no conflict of interest. 


\section{References}

BACON, HE. and SMITH, CH. The arterial supply of the distal colon pertinent to abdominoperineal proctosigmoidectomy with preservation of sphincter mechanism. Annals of Surgery, 1948, vol. 127, n. 1, p. 28-33. PMid:17859063. http://dx.doi.org/10.1097/00000658194801000-00003.

BASMAJIAN, JV. The main arteries of the large intestine. Surgery, Gynecology \& Obstetrics, 1955, vol. 101, n. 5, p. 585-591. PMid:13267683.

BOWER, TC. Ischemic colitis. The Surgical Clinics of North America, 1993, vol. 73, n. 5, p. 1037-1053. PMid:8378827. http://dx.doi. org/10.1016/S0039-6109(16)46139-6.

CALAFIORE, AM., DI GIAMMARCO, G., TEODORI, G., MALL, SP., VITOLLA, G. and FINO, C. Myocardial revascularization with multiple arterial grafts. Asian Cardiovascular o Thoracic Annals, 1995, vol. 3, n. 3-4, p. 95-102. http://dx.doi.org/10.1177/0218 49239500300402 .

FARMAN, J. Ischemic colitis. Abdominal Imaging, 1995, vol. 20, n. 1, p. 85-86. PMid:7894309. http://dx.doi.org/10.1007/BF00199655.

GOLLIGHER, JC. Surgical anatomy and physiology of the colon, rectum, and anus. In Tindall \& Cassell. Surgery of anus, rectum and colon. 2nd ed. London: Bailliere, Tindall \& Cassell, 1967. p. 1-54.

GRIFFITHS, JD. Surgical anatomy of the blood supply of the distal colon. Annals of the Royal College of Surgeons of England, 1956, vol. 19, n. 4, p. 241-256. PMid:13363265.

LONGO, WE., BALLANTYNE, GH. and GUSBERG, RJ. Ischemic colitis: patterns and prognosis. Diseases of the Colon and Rectum, 1992, vol. 35, n. 8, p. 726-730. PMid:1643995. http://dx.doi. org/10.1007/BF02050319.

MICHELS, NA., SIDDHARTH, P., KORNBLITH, PL. and PARKE, WW. The variant blood supply to the descending colon, rectosigmoid and rectum based on 400 dissections. Its importance in regional resections- a review of medical literature. Diseases of the Colon and Rectum, 1965, vol. 8, n. 4, p. 251-278. PMid:14323715. http:// dx.doi.org/10.1007/BF02617894.

MIKKELSEN, WP. Treatment of chronic intestinal ischemia. In RUTHERFORD, RB. (Ed.). Vascular surgery. 4th ed. WB Saunders: Philadelphia, Pa, USA, 1995. p. 1301-1311

NELSON, TM., POLLAK, R., JONASSON, O. and ABCARIAN, $\mathrm{H}$. Anatomic variants of the celiac, superior mesenteric and inferior mesenteric arteries and their clinical relevance. Clinical Anatomy (New York, N.Y.), 1988, vol. 1, n. 2, p. 75-91. http://dx.doi. org/10.1002/ca.980010202.
OSAWA, T., FENG, XY., SASAKI, N., NAGATO, S., MATSUMOTO, Y., ONODERA, M., NARA, E., FUJIMURA, A. and NOZAKA, Y. Rare case of the inferior mesenteric artery and the common hepatic artery arising from the superior mesenteric artery. Clinical Anatomy (New York, N.Y.), 2004, vol. 17, n. 6, p. 518-521. PMid:15300873. http://dx.doi.org/10.1002/ca.10234.

SIDDHARTH, P. and RAVO, B. Colorectal neurovasculature and anal sphincter. The Surgical Clinics of North America, 1988, vol. 68, n. 6, p. 1185-1200. PMid:3194816. http://dx.doi.org/10.1016/ S0039-6109(16)44680-3.

SINKEET, S., PHILIP, M., JOHNSTONE, M. and HASSAN, S. Branching pattern of inferior mesentric artery in a black African population: a dissection study. ISRN Anatomy, 2013, vol. 2013, n. 962904, p. 1-4. PMid:25969825. http://dx.doi.org/10.5402/2013/962904.

TERAYAMA, H., NAITO, M., IIMURA, A. and ITOH, M. A rare case of inferior mesenteric artery arising from the superior mesenteric artery with review of the literature. Surgical and Radiologic Anatomy, 2008, vol. 30, n. 2, p. 159-165. PMid:18189117. http://dx.doi. org/10.1007/s00276-007-0298-x.

VAN TONDER, JJ., BOON, JM., BECKER, JHR. and VAN SCHOOR, AN. Anatomical considerations on Sudeck's critical point and its relevance to colorectal surgery. Clinical Anatomy (New York, N.Y.), 2007, vol. 20, n. 4, p. 424-427. PMid:17022033. http:// dx.doi.org/10.1002/ca.20417.

YAMAZAKI, T., SHIRAI, Y., SAKAI, Y. and HATAKEYAMA, K. Ischemic stricture of the rectosigmoid colon caused by division of the superior rectal artery below Sudeck's point during sigmoidectomy: report of a case. Surgery Today, 1997a, vol. 27, n. 3, p. 254-256. PMid:9068109. http://dx.doi.org/10.1007/BF00941656.

YAMAZAKI, T., SHIRAI, Y., TADA, T., SASAKI, M., SAKAI, Y. and HATAKEYAMA, $\mathrm{K}$. Ischemic colitis arising in watershed areas of the colonic blood supply: a report of two cases. Surgery Today, 1997b, vol. 27, n. 5, p. 460-462. PMid:9130353. http://dx.doi. org/10.1007/BF02385714.

YOO, SJ., KU, MJ., CHO, SS. and YOON, SP. A case of the inferior mesenteric artery arising from the superior mesenteric artery in a Korean woman. Journal of Korean Medical Science, 2011, vol. 26, n. 10, p. 1382-1385. PMid:22022194. http://dx.doi.org/10.3346/ jkms.2011.26.10.1382.

Received December 31, 2015 Accepted November 15, 2016 